\title{
Effects of Yoga Training Aerobic Training and Detraining On Muscular Strength among College Boys
}

\author{
*Dr Baljit Singh Sekhon and **Dr P. V. Shelvam \\ *Deputy Director of Sports and Head, Nagaland University, Lumami, Nagaland.India \\ * *Professor, Department of Physical Education and Sports Sciences, Annamalai University, Annamalainagar, \\ India
}

\begin{abstract}
The purpose of the study was to find out the effects of yoga training aerobic training and detraining on muscular strength among college boys. To achieve this purpose of the study, forty five college boys were selected as subjects who were studied various department in the Nagaland University, Lumami. The selected subjects were aged between 18 to 21 years. The selected subjects were randomly divided into three groups of 15 subjects each group. Group one acted as experimental group I (yoga training) and group two acted as experimental group II (aerobic training) and group three acted as control group. The subjects were tested on selected criterion variable such as muscular strength prior to and immediately after the training period. The selected criterion variable such as muscular strength was measured by grip dynamometer. The collected data from the three groups before, during and after the experimentation was statistically analyzed by using two-way $(3 \times 3)$ factorial analysis of variance with last factor repeated measures. The data collected from the three groups at post test and detraining (three cessation) was statistically analyzed by using two way $(3 \times 4)$ factorial ANOVA with last factor repeated measures. Two way factorial ANOVA was used to find out the significant differences if any, the Scheffe's test is applied as post hoc test to determine which of the paired mean had significant differences. The 0.05 level of confidence was fixed to test the significance. The result of the present study has revealed that there was a significant difference among the experimental and control group on muscular strength.
\end{abstract}

Key words: yoga training-aerobic training-physical fitness variables

\section{Indroduction}

Physical Education aims to keep people "healthy". The Physical Education / health programmed provide boys and girls with accurate and significant knowledge related to their individual needs and interest. There is also concern for health services and healthy physical and emotional environment. Physical fitness is more than is not being sick or merely being well. It is different from resistance or immunity from disease. Physical fitness therefore is an essential quality in humans. Yoga is a systematic and methodological process to control and develop the mind and body to attain good health, balance of mind and self-realization. Thought yoga has the potential power to make us healthy added to our vigor, still most of the people lack the knowledge of systematic practice of yoga. They perform yogic exercises for a short period and when their health improves, they discontinue the practices. For this reason, the effective results of yogic practices cannot be determined perfectly. Many scientists, doctors, psychologists etc, all over the world are extensively studying the beneficial aspects of yoga which encourages us to attain positive health through yoga. Aerobic exercise comprises innumerable forms. In general, it is performed at a moderate level of intensity over a relatively long period of time. For example, running a long distance at a moderate pace is an aerobic exercise, but sprinting is not. Playing singles tennis, with near-continuous motion, is generally considered aerobic activity, while golf or two person team tennis, with brief bursts of activity punctuated by more frequent breaks, may not be predominantly aerobic.

\section{Me Thodology}

The purpose of the study was to find out the effects of yoga training aerobic training and detraining on muscular strength among college boys. To achieve this purpose of the study, forty five college boys were selected as subjects who were studied various departments in the Nagaland University, Lumami. The selected subjects were aged between 18 to 21 years. The selected subjects were randomly divided into three groups of 15 subjects each group. Group one acted as experimental group I (yoga training) and group two acted as experimental group II (aerobic training) and group three acted as control group. The subjects were tested on selected criterion variable such as muscular strength prior to and immediately after the training period. The selected criterion variable such as muscular strength was measured by grip dynamometer. The collected data from the three groups before, during and after the experimentation was statistically analyzed by using two-way 
$(3 \times 3)$ factorial analysis of variance with last factor repeated measures. The data collected from the three groups at post test and detraining (three cessation) was statistically analyzed by using two way $(3 \times 4)$ factorial ANOVA with last factor repeated measures. Two way factorial ANOVA was used to find out the significant differences if any, the Scheffe's test is applied as post hoc test to determine which of the paired mean had significant differences. The 0.05 level of confidence was fixed to test the significance.

\section{Results}

Findings: The mean and standard deviation values on muscular (grip) strength of pretest, mid test, posttest, first cessation, second cessation and third cessation period scores of yogic, aerobic and control group are given in table I.

Table I: Mean And S.D. Values On Muscular Strengthof Pretest, Mid Test, Posttest, First Cessation, Second Cessation And Third Cessation Period Scores Of Yogic, Aerobic And Control Groups

\begin{tabular}{|c|c|c|c|c|c|c|c|}
\hline \multicolumn{2}{c|}{ Group } & Pretest & Mid test & Post test & I cessation & II cessation & III cessation \\
\hline \multirow{2}{*}{ Yogic } & Mean & 16.80 & 18.13 & 19.13 & 18.47 & 17.87 & 17.40 \\
\cline { 2 - 8 } & S.D & 1.69 & 1.55 & 1.55 & 1.46 & 1.41 & 1.51 \\
\hline \multirow{2}{*}{ Aerobic } & Mean & 16.93 & 18.87 & 19.93 & 18.67 & 17.93 & 17.20 \\
\cline { 2 - 9 } & S.D & 1.98 & 1.25 & 1.22 & 1.29 & 1.34 & 1.64 \\
\hline \multirow{2}{*}{ Control } & Mean & 16.87 & 16.93 & 17.07 & 17.13 & 17.13 & 17.20 \\
\cline { 2 - 9 } & S.D & 1.46 & 1.34 & 1.28 & 1.19 & 1.19 & 1.19 \\
\hline
\end{tabular}

Table I shows the analyzed data of muscular strength. The pre means for yogic, aerobic and control group are 16.80, 16.93 and 16.87 respectively. The mid test means for yogic, aerobic and control group are $18.13,18.87$ and 16.93 respectively. The post means for yogic, aerobic and control group are 19.13, 19.93 and 17.07 respectively. The I cessation means for yogic, aerobic and control group are 18.47, 18.67 and 17.13 respectively. The II cessation means for yogic, aerobic and control group are 17.87, 17.93 and 17.13 respectively and the III cessation means for yogic, aerobic and control group are 17.40, 17.21 and 17.13 respectively.

The data on muscular strength during training period have been analyzed by two way factorial ANOVA $(3 \times 3)$ with repeated measures on last factor and the results are presented in Table II.

Table II it is clear that the obtained ' $F$ ' ratio for groups, different stages of testing period and interaction are 4.796, 214.46 and 45.85 respectively, which was greater than the table value $(2$ and $42=3.22,2$ and $84=3.106$ and 4 and $84=2.482$ respectively). The result of the study indicates that, significant differences exist among the experimental and control groups irrespective of different stages of testing muscular strength.

\section{Table II: TWO WAY ANALYSIS OF VARIANCE WITH LAST FACTOR REPEATED MEASURES ON MUSCULAR STRENGTH OF CONTROL AND EXPERIMENTAL GROUPS AT THREE DIFFERENT TESTING PERIODS}

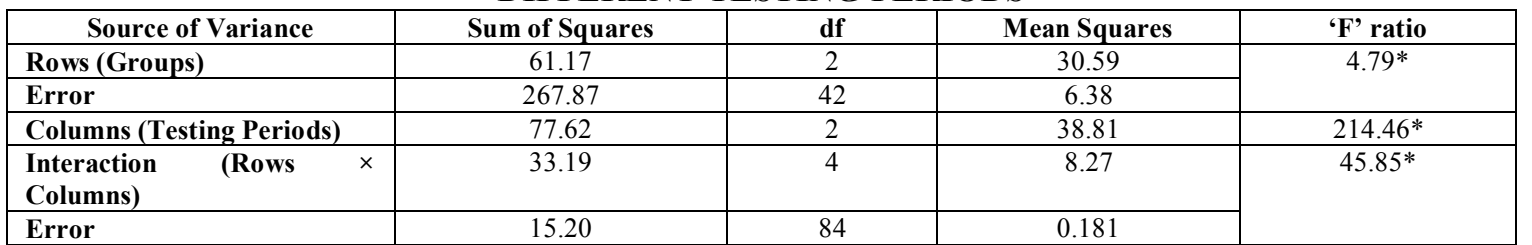

The results of the study indicate that significant differences exist in the interaction effect (between groups and tests) on muscular strength. Since the interaction effect is significant, the simple effect test has been applied as follow up test and it is presented in Table III.

Table III: THE SIMPLE EFFECT SCORES OF GROUPS AT THREE DIFFERENT TESTING PERIODS ON MUSCULAR STRENGTH

\begin{tabular}{|l|c|c|c|c|}
\hline \multicolumn{1}{|c|}{ Source of Variance } & Sum of Squares & df & Mean Squares & 'F' ratio \\
\hline Groups and Pre test & 0.067 & 2 & 0.034 & 0.185 \\
\hline Groups and Mid test & 14.289 & 2 & 7.145 & $39.472^{*}$ \\
\hline Groups and Post test & 32.822 & 2 & 16.411 & $90.669^{*}$ \\
\hline Tests and Control Group & 0.156 & 2 & 0.078 & 0.431 \\
\hline Tests and Yoga Group & 20.556 & 2 & 10.278 & $56.785^{*}$ \\
\hline Tests and Aerobic Group & 34.689 & 2 & 17.345 & \\
\hline Error & 15.200 & 84 & 0.181 & \\
\hline
\end{tabular}


Table III shows that the obtained ' $F$ ' ratio for groups at mid and post test are 39.472 and 90.669 respectively. The result of the study indicates that significant difference on muscular strength exists between groups at mid and post test. Further it denotes that the obtained ' $F$ ' ratio values for tests of yogic and aerobic group are56.785 and 95.826 respectively. The result of the study indicates that significant difference on muscular strength among the tests of yogic and aerobic group.

Whenever, the obtained ' $F$ ' ratio value is found to be significant, the Scheffe's post hoc test is applied to find out the paired mean differences and it is presented in Tables IV and V.

Table IV: SCHEFFĚ $S$ TEST FOR THE DIFFERENCE BETWEEN THE DIFFERENT GROUPS ON MUSCULAR STRENGTH

\begin{tabular}{|c|c|c|c|c|}
\hline Testing Periods & Yogic Group & Aerobic Group & Control Group & Mean Difference \\
\hline \multirow{3}{*}{ Pre test } & 16.80 & & 16.87 & 0.07 \\
\cline { 2 - 5 } & & 16.93 & 16.87 & 0.06 \\
\cline { 2 - 5 } & 16.80 & 16.93 & 16.93 & $1.20^{*}$ \\
\hline \multirow{3}{*}{ Mid test } & 18.13 & & 16.93 & $1.94^{*}$ \\
\cline { 2 - 5 } & & 18.87 & & $0.74^{*}$ \\
\hline \multirow{3}{*}{ Post test } & 18.13 & 18.87 & 17.17 & $2.06^{*}$ \\
\cline { 2 - 5 } & 19.13 & 19.93 & 17.07 & $2.86^{*}$ \\
\cline { 2 - 5 } & & 19.93 & & $0.80^{*}$ \\
\hline
\end{tabular}

From the above table it has been observed that the mean difference values on muscular strength during the mid test between the yogic and control group are 1.20, aerobic and control group are 1.94 and yogic and aerobic group are 0.74 . The post test between the yogic and control group are 2.06, aerobic and control group are 2.86 and yogic and aerobic group are 0.80 . There is significant difference among the three groups which denotes that both the experimental groups are significantly better on muscular strength than the control group.

Table V: Scheffẽ $S$ Test For The Difference Between The Each Group At Different Testing Periods On Muscular Strength

\begin{tabular}{|c|c|c|c|c|}
\hline Group & Pre test & Mid test & Post test & Mean Difference \\
\hline \multirow{3}{*}{ Yogic } & 16.80 & 18.13 & & $1.33^{*}$ \\
\cline { 2 - 5 } & 16.80 & & 19.13 & $2.33^{*}$ \\
\cline { 2 - 5 } & & 18.13 & 19.13 & $1.00^{*}$ \\
\hline \multirow{3}{*}{ Aerobic } & 16.93 & 18.87 & 19.93 & $3.94^{*}$ \\
\cline { 2 - 5 } & 16.93 & & 19.93 & $1.06^{*}$ \\
\cline { 2 - 5 } & & 18.87 & & 0.06 \\
\cline { 2 - 5 } Control & 16.87 & 16.93 & 17.07 & 020 \\
\cline { 2 - 5 } & 16.87 & & 17.07 & 0.14 \\
\hline
\end{tabular}

From the above table it has been observed that the mean difference values on muscular strength of yogic group during the pre test to mid test are 1.33, pre test to post test are 2.33 and mid test to post test are 1.00. The mean differences of aerobic group pre test to mid test are 1.94, pre test to post test are 3.00 and mid test to post test are 1.06. There is significant difference during the pre test to mid test, pre test to post test and mid test to post test period.

\section{Table VI: TWO WAY ANALYSIS OF VARIANCE WITH LAST FACTOR REPEATED MEASURES ON MUSCULAR STRENGTH OF CONTROL AND EXPERIMENTAL GROUPS AT FOUR DIFFERENT TESTING PERIODS}

\begin{tabular}{|l|c|c|c|c|}
\hline \multicolumn{1}{|c|}{ Source of Variance } & Sum of Squares & df & Mean Squares & 'F' ratio \\
\hline Rows (Groups) & 58.211 & 2 & 29.106 & $4.13^{*}$ \\
\hline Error (Testing & 296.10 & 42 & 7.050 & $114.48^{*}$ \\
\hline $\begin{array}{l}\text { Columns } \\
\text { Periods) }\end{array}$ & 52.061 & 3 & 17.354 & $38.03^{*}$ \\
\hline $\begin{array}{l}\text { Interaction (Rows } \\
\text { Columns) }\end{array}$ & 34.589 & 6 & 5.765 & \\
\hline Error & 19.10 & 126 & 0.152 & \\
\hline
\end{tabular}

Table VI it is clear that the obtained ' $F$ ' ratio for groups, different stages of testing period and interaction are 4.13, 114.48 and 38.03 respectively, which was greater than the table value $(2$ and $42=3.22,3$ and $126=2.68$ and 6 and $126=2.17$ respectively). The result of the study indicates that, significant differences exist among groups at each test and also significant differences between tests for each group on muscular strength. 


\section{Table VII: THE SIMPLE EFFECT SCORES OF GROUPS AT THREE DIFFERENT}

TESTING PERIODS ON MUSCULAR STRENGTH

\begin{tabular}{|l|c|c|c|c|}
\hline \multicolumn{1}{|c|}{ Source of Variance } & Sum of Squares & df & Mean Squares & 'F' ratio \\
\hline Groups and Post test & 32.822 & 2 & 16.411 & $107.97^{*}$ \\
\hline Groups and I Cessation & 10.422 & 2 & 5.211 & $34.28^{*}$ \\
\hline Groups and II Cessation & 2.956 & 2 & 1.478 & 0.10 \\
\hline Groups and III Cessation & 0.20 & 2 & 0.147 & 0.66 \\
\hline Tests and Control Group & 0.44 & 3 & 2.82 & 0.97 \\
\hline Tests and Yoga Group & 8.461 & 3 & 6.793 & $18.56^{*}$ \\
\hline Tests and Aerobic Group & 20.378 & 3 & 0.152 & $44.69^{*}$ \\
\hline Error & 19.10 & 126 & \multicolumn{2}{c|}{} \\
\hline
\end{tabular}

Table VII shows that the obtained ' $F$ ' ratio for groups at post, I cessation and II cessation are 107.97, 34.28 and 9.72 respectively. The result of the study indicates that significant difference on muscular strength exists between groups at post test, I cessation and II cessation. Further it denotes that the obtained ' $F$ ' ratio values for tests of yogic and aerobic group are 18.56 and 44.69 respectively. The result of the study indicates that significant difference on muscular strength among the tests of yogic and aerobic group.

Whenever, the obtained ' $\mathrm{F}$ ' ratio value is found to be significant, the Scheffe's post hoc test is applied to find out the paired mean differences and it is presented in Tables VIII and IX.

\section{Table VIII: SCHEFFĚ $S$ TEST FOR THE DIFFERENCE BETWEEN THE DIFFERENT} GROUPS AT EACH TRAINING CESSATION ON MUSCULAR STRENGTH

\begin{tabular}{|c|c|c|c|c|}
\hline Testing Periods & Yogic Group & Aerobic Group & Control Group & Mean Difference \\
\hline \multirow[t]{3}{*}{ Post test } & 19.13 & & 17.07 & $2.06^{*}$ \\
\hline & & 19.93 & 17.07 & $2.86^{*}$ \\
\hline & 19.13 & 19.93 & & $0.80^{*}$ \\
\hline \multirow[t]{3}{*}{ I Cessation } & 18.47 & & 17.13 & $1.34 *$ \\
\hline & & 18.67 & 17.13 & $1.54 *$ \\
\hline & 18.47 & 18.67 & & 0.20 \\
\hline \multirow[t]{3}{*}{ II Cessation } & 17.87 & & 17.13 & $0.74 *$ \\
\hline & & 17.93 & 17.13 & $0.80^{*}$ \\
\hline & 17.87 & 17.93 & & 0.06 \\
\hline \multirow[t]{3}{*}{ III Cessation } & 17.40 & & 17.20 & 0.20 \\
\hline & & 17.20 & 17.20 & 0.00 \\
\hline & 17.40 & 17.20 & & 0.20 \\
\hline
\end{tabular}

From the above table it has been observed that the mean difference values on muscular strength is found to be significant for the three groups during the post test, I cessation and II cessation.

\section{Table IX: SCHEFFĔ $S$ TEST FOR THE DIFFERENCE BETWEEN THE EACH GROUP AT DIFFERENT TESTING PERIODS AT TRAINING CESSATION ON MUSCULAR} STRENGTH

\begin{tabular}{|c|c|c|c|c|c|}
\hline Group & Post test & I Cessation & II Cessation & III Cessation & Mean Difference \\
\hline \multirow{4}{*}{ Yogic } & 19.13 & 18.46 & & & $0.67^{*}$ \\
\hline & 19.13 & & & 17.40 & $1.73 *$ \\
\hline & & 18.46 & & 17.40 & $1.06^{*}$ \\
\hline & & & 17.87 & 17.40 & $0.47 *$ \\
\hline \multirow[t]{5}{*}{ Aerobic } & 19.93 & 18.67 & & & $1.26^{*}$ \\
\hline & 19.93 & & & 17.20 & $2.73 *$ \\
\hline & & 18.67 & 17.93 & & $0.64 *$ \\
\hline & & 18.67 & & 17.20 & $1.47 *$ \\
\hline & & & 17.93 & 17.20 & $0.73 *$ \\
\hline \multirow[t]{3}{*}{ Control } & 17.07 & 17.13 & & & 0.06 \\
\hline & 17.07 & & 17.13 & & 0.06 \\
\hline & & & 17.13 & 17.20 & 0.07 \\
\hline
\end{tabular}

From the above table it has been observed that the mean difference values on muscular strength of yogic group and aerobic group have significant difference during the all training cessation. 


\section{Discussion/Conclusions}

The results of the present study indicate that both the experimental groups have significantly increased the muscular strength when compared to the control group. The result of the study is in consonance with Madanmohan et al, (2008), Chen et al, (2009) and Licl et al, (2006). Further, the improvement of muscular strength is significantly higher for the aerobic group when compared to yogic group during training periods. But during the training cessation periods both the experimental groups has significantly reduced gradual manner for first and second cessation period.

\section{Referrence}

[1]. Chen T.L, et al., (2009) "The Effect of Yoga Exercise Intervention on Health Related Physical Fitness in School-Age Asthmatic Children", The Journal of Nursing, Vol II.

[2]. Clarke David H. and H. Harrison Clarke, (1988) Advanced Statistics, (New Jersey: Prentice Hall Inc.,), 31-38.

[3]. Cooper, H. Kenneth, (2009) Aerobics, Bantan Publishing, www.en.vikipedia.org.

[4]. Davis. R.J., et. al., (1991) Physical Education and The Study of Sport, England:Wolf Publishing Ltd.,

[5]. Exercise: 7 Benefits of Regular Exercise, www.mayoclinic.com/health/exercise/HQ01676

[6]. Hertler L, et. al., (1992) "Water Running and the Maintanence of Maximum Oxygen Consumption and Leg Strength in Women", Medicine and Science in Sports and Exercise, 24, S23.

[7]. Licl et al., (2006) "The Effectiveness of an Aerobic Exercise Intervention on Worksite Health - Related Physical Fitness - a case in a High-Tech Company", Chang Gung Medical Journal, Vol I.

[8]. Madanmohan et al., (2008) "Effect of Six Week Yoga Training on Weight Loss Following Step Test, Respiratory Pressure, Handgrip Strength and Hand Grip Endurance in Young Healthy Subjects", Indian Journal of Physiology and Pharmacology, Vol.II.

[9]. Pradhan, P.K., (2008) "Yogic Practices for Health and Sports Performance", Indian Journal of Yoga Exercises \& Sports Sciences and Physical Education, Vol. II., 12.

[10]. Stevan Roy and Richard Irvin, Sports Medicine Prevention, Evaluation, Management and Rehabilitation (Englewood cliffs:Prentice Hall Inc. 1993) 64. 